\section{It is time for consensus on} 'consensus statements'

\author{
Paul Blazey (10 , 1,2 Kay M Crossley (10, ${ }^{3}$ Clare L Ardern (1) , 1,3,4 \\ Marienke van Middelkoop (i), ${ }^{5}$ Alex Scott (1) , ${ }^{2,6}$ Karim M Khan (1) ${ }^{4}$
}

The International Olympic Committee has published 27 'consensus statements' since 2004. ${ }^{1}$ Many of them are heavily downloaded and highly cited. Several have influenced health policy and societal behaviour. Some consensus statements are so well-known they go by just one name in context: 'Berlin' means concussion, 'Doha' is synonymous with groin pain, and 'Bern' evokes return to play guidelines.

Despite their eminence, even the most respected consensus statements have limitations: relevant stakeholders are absent from the consensus process; authors inadequately report the method of evidence synthesis; consensus group members may be 'coerced' to agree; and the reports often fail to capture the rich discussion that occurs during a panel meeting.

We critically examine methods that underpin sport and exercise medicine consensus statements. Specifically, we: (1) question whether consensus statements deserve their prestige; (2) highlight bias in the current methods of developing consensus and (3) propose future steps to improve the quality of consensus statements by using reporting guidelines.

\section{DO CONSENSUS STATEMENTS DESERVE THE PRESTIGE THEY ARE AFFORDED?}

Expert opinion sits at the base of the evidence pyramid but when those experts gather, and take recent systematic reviews into account, their output-consensus

${ }^{1}$ Center for Hip Health and Mobility, The University of British Columbia, Vancouver, British Columbia, Canada ${ }^{2}$ Department of Physiotherapy, The University of British Columbia Faculty of Medicine, Vancouver, British Columbia, Canada

${ }^{3}$ Sport and Exercise Medicine Research Centre, La Trobe University, Bundoora, Victoria, Australia

${ }^{4}$ Family Practice \& Kinesiology, The University of British Columbia, Vancouver, British Columbia, Canada

${ }^{5}$ General Practice, Erasmus Medical Center, Rotterdam, The Netherlands

${ }^{6}$ Centre for Hip Health and Mobility, The University of British Columbia Faculty of Medicine, Vancouver, British Columbia, Canada

Correspondence to Paul Blazey, Center for Hip Health and Mobility, The University of British Columbia, Vancouver V5Z 1M9, British Columbia, Canada; paul.blazey@ubc.ca address Key Questions A-D. statements-are given great weight. Consensus statements are some of the most downloaded and cited publications. They can inform state and sporting policy, ${ }^{2}$ which opens up the potential to impact individual behaviour and eventually patient outcomes. Judging how much to trust consensus statement recommendations can be difficult (see figure 1). How can the research community (consensus creators, Journal editors, media channels) ensure the great weight given to consensus statements is supported by a scientific, rigorous, transparent, replicable and equitable process?

\section{NOT ALL CONSENSUS STATEMENTS ARE EQUAL: BEWARE THE BIASES}

Delphi or the 'modified' Delphi method are the most common forms of developing consensus. However, nominal group technique, consensus conference and the RAND-UCLA appropriateness methods are also well established. ${ }^{34}$ There has been little scrutiny of which consensus methods suit a specific research question. Is modified Delphi or a consensus conference the best method to agree on research definitions and does the choice of consensus method affect the outcome?

Many consensus statements were authored by a group of eminent scientists/ clinicians gathering to decide what is best for the field. The statements themselves may be informed by a systematic review or may come from individuals selecting statements without oversight or feedback, leading to potentially biased questions or statements. This informal consensus, 'consensus by people standing around a BBQ'-has been criticised as generating long form editorials-no more than 'expert-based blockbusters'. 5 Those who lead consensus projects must carefully consider who should be 'in the room'and who is notably absent. In the 2020s, patient partners are oft-forgottenbut essential-contributors to quality consensus statements. ${ }^{6}$ And, selection of 'expert' panels can exacerbate problems of equity, diversity or inclusion in a field, perpetuating an uneven social balance.

Unless consensus methods are specifically designed to highlight disagreements, methods such as the Delphi technique may introduce 'herding bias' via betweenround feedback comparing individuals to their peers. Methods of measuring consensus may even remove outliers' views, artificially elevating 'agreement' among participants. ${ }^{7}$ This runs the risk of suppressing important minority views. ${ }^{8}$ Agreement 'at all costs' runs the risk of producing watered-down recommendations, where groups report only their lowest common denominator, and merely reinforce the status quo. ${ }^{9}$ Methods and reporting guidelines that include divergent opinions should be encouraged; this allows the reader to make up their own mind on the strength of a statement.

\section{MOVING FORWARD: CAN WE ACHIEVE CONSENSUS ON CONSENSUS?}

We see an opportunity to move towards an evidence-informed consensus process for sport and exercise medicine. The Guidelines on Conducting and Reporting

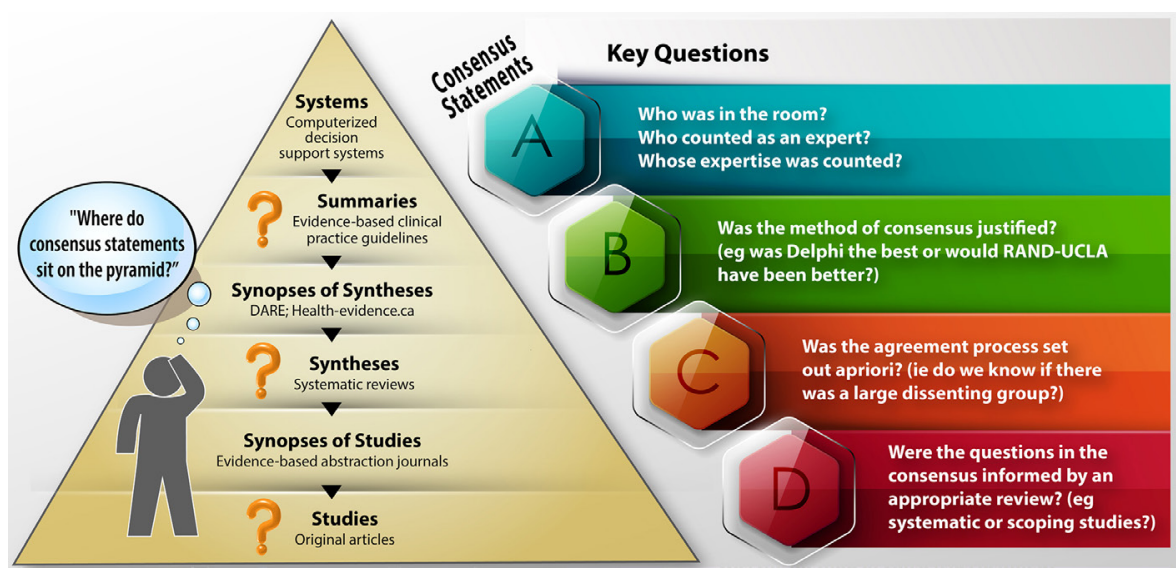

Figure 1 Should you trust this consensus statement? Trustworthy consensus statements should 
DElphi Studies (CREDES) in palliative care provides a model ('Bright Spot') for groups to conduct and report on Delphi studies. ${ }^{10}$ CREDES includes 16 recommendations. They include:

- Carefully consider and report criteria for the selection of 'experts'. Be transparent when recruiting the expert panel, report panel participant details, their expertise on the topic in question, and include response rates for all iterations of the Delphi process including the response from each group (clinicians, researchers, patients, etc).

- Justify your method of consensus development, including why it is relevant to answer your question, and report any methodological alterations specific to your study, including why they were necessary.

- Define a priori what level of agreement is considered consensus for the group, and whether you intend to actively generate consensus or highlight discordance among experts.

- Recognise consensus is not analogous with 'the correct' answer to a question. Recognise opposing opinions in your report, and attempt to externally validate results before publication.

CREDES offers one template to report consensus. Whichever method of consensus generation is chosen, researchers should aspire to answer the questions above.

Consensus statements have influenced research direction and clinical practice. Many of the current methods of attaining consensus have been little scrutinised in their 50-year history. The reporting of these methods has usually been sketchy. Our field can improve by building consensus on consensus-how to achieve it, how to interpret it, and how to report it.

Correction notice This article has been corrected since it published Online First. The title has been corrected.

Twitter Paul Blazey @blazey85, Kay M Crossley @kaymcrossley, Clare LArdern @clare_ardern, Marienke van Middelkoop @mvanmiddelkoop, Alex Scott @alex_scott_ubc and Karim M Khan @KarimKhan_IMHA

Contributors All authors contributed to the conception and development of this paper, led by PB.

Funding Professor Khan holds a Canadian Institute of Health Research (CIHR) Scientific Director research grant - SOP-154942.All other authors have not declared a specific grant for this research from any funding agency in the public, commercial or not-forprofit sectors.

Competing interests None declared.

Patient consent for publication Not applicable.

Provenance and peer review Not commissioned; externally peer reviewed.

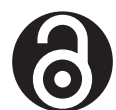

\section{OPEN ACCESS}

Open access This is an open access article distributed in accordance with the Creative Commons Attribution Non Commercial (CC BY-NC 4.0) license, which permits others to distribute, remix, adapt, build upon this work non-commercially, and license their derivative works on different terms, provided the original work is properly cited, appropriate credit is given, any changes made indicated, and the use is non-commercial. See: http://creativecommons.org/ licenses/by-nc/4.0/.

(c) Author(s) (or their employer(s)) 2021. Re-use permitted under CC BY-NC. No commercial re-use. See rights and permissions. Published by BMJ.

\section{A) Check for updates}

To cite Blazey P, Crossley KM, Ardern CL, et al. Br J Sports Med Epub ahead of print: [please include Day Month Year]. doi:10.1136/bjsports-2021-104578
Accepted 14 September 2021

Br J Sports Med 2021;0:1-2.

doi:10.1136/bjsports-2021-104578

ORCID iDs

Paul Blazey http://orcid.org/0000-0002-8149-9514 Kay M Crossley http://orcid.org/0000-0001-5892-129X

Clare L Ardern http://orcid.org/0000-0001-8102-3631 Marienke van Middelkoop http://orcid.org/0000-00016926-0618

Alex Scott http://orcid.org/0000-0003-0366-8404

Karim M Khan http://orcid.org/0000-0002-9976-0258

\section{REFERENCES}

1 IOC. IOC consensus statements IOC medical and scientific Commission website, 2021. Available: https:// www.olympic.org/medical-and-scientific-commission\# consensus-statements [Accessed 22 Jul 2021].

2 Canadian Guideline on Concussion in Sport, 2021. Available: https://www. parachute.ca/en/professionalresource/concussion-collection/canadian-guideline-onconcussion-in-sport/ [Accessed 14 May 2021].

3 Murphy MK, Black NA, Lamping DL, et al. Consensus development methods, and their use in clinical Guideline development. Health Technol Assess 1998;2:1-88

4 Nair R, Aggarwal R, Khanna D. Methods of formal consensus in classification/diagnostic criteria and Guideline development. Semin Arthritis Rheum 2011:41:95-105

5 loannidis JPA, Thombs BD. A user's guide to inflated and manipulated impact factors. Eur J Clin Invest 2019;49:e13151.

6 Belton J, Hoens A, Scott A, et al. Patients as partners in research: it's the right thing to do. J Orthop Sports Phys Ther 2019:49:623-6.

7 Shrier I. Consensus statements that fail to recognise dissent are flawed by design: a narrative review with 10 suggested improvements. Br J Sports Med 2020:bjsports-2020-102545.

8 Jandhyala R. Delphi, non-RAND modified Delphi, RAND/UCLA appropriateness method and a novel group awareness and consensus methodology for consensus measurement: a systematic literature review. Curr Med Res Opin 2020;36:1873-87.

9 Scott EA, Black N. When does consensus exist in exper panels? J Public Health 1991:13:35-9.

10 Jünger S, Payne SA, Brine J, et al. Guidance on conducting and reporting Delphi studies (CREDES) in palliative care: recommendations based on a methodological systematic review. Palliat Med 2017:31:684-706. 